\author{
S.V. Sudoplatov \\ Sobolev Institute of Mathematics, Novosibirsk, Russia; \\ Novosibirsk State Technical University, Russia; \\ Novosibirsk State University, Russia; \\ Institute of Mathematics and Mathematical Modeling CS MES RK, Almaty, Kazakhstan \\ (E-mail: sudoplat@math.nsc.ru)
}

\title{
On generic structures preserving elementary equivalence and elementary embeddability
}

\begin{abstract}
We consider criteria for elementary equivalence and elementary embeddability for generic structures. They use classical characterizations for the general case. The criterion for elementary equivalence is based on the well known Fraïssé-Taimanov-Ehrenfeucht overturning method. The criterion for elementary embeddability uses the known Tarski-Vaught test.
\end{abstract}

Keywords: generic structure, elementary equivalence, Fraïssé-Taimanov-Ehrenfeucht's method, elementary embeddability, Tarski-Vaught test.

We consider criteria for elementary equivalence and elementary embeddability for generic structures [1-6]. They are based on classical characterizations for the general case. The criterion for elementary equivalence uses the well known Fraïssé-Taimanov-Ehrenfeucht overturning method [7-12]. The criterion for elementary embeddability is based on the Tarski-Vaught test [11, 13].

\section{Preliminaries}

We consider collections of sentence and formulas in first order logic over a language $\Sigma$. Thus, as usual, $\vdash$ means proof from no hypotheses deducing $\vdash \varphi$ for a formula $\varphi$ of language $\Sigma$, which may contain function symbols and constants. If deducing $\varphi$, hypotheses in a set $\Phi$ of formulas can be used, we write $\Phi \vdash \varphi$. Usually $\Sigma$ will be fixed in context and not mentioned explicitly.

Below we write $X, Y, Z, \ldots$ for finite sets of variables, and denote by $A, B, C, \ldots$ finite sets of elements, as well as finite sets in structures, or else the structures with finite universes themselves.

In diagrams, $A, B, C, \ldots$ denote finite sets of constant symbols disjoint from the constant symbols in $\Sigma$ and $\Sigma(A)$ is the vocabulary with the constants from $A$ adjoined. $\Phi(A), \Psi(B), \mathrm{X}(C)$ stand for $\Sigma$-diagrams (of sets $A$, $B, C)$, that is, consistent sets of $\Sigma(A)-, \Sigma(B)-, \Sigma(C)$-sentences, respectively.

Below we assume that for any considered diagram $\Phi(A)$, if $a_{1}, a_{2}$ are distinct elements in $A$ then $\neg\left(a_{1} \approx a_{2}\right) \in \Phi(A)$. This means that if $c$ is a constant symbol in $\Sigma$, then there is at most one element $a \in A$ such that $(a \approx c) \in \Phi(A)$.

If $\Phi(A)$ is a diagram and $B$ is a set, we denote by $\left.\Phi(A)\right|_{B}$ the set $\{\varphi(\bar{a}) \in \Phi(A) \mid \bar{a} \in B\}$. Similarly, for a language $\Sigma$, we denote by $\left.\Phi(A)\right|_{\Sigma}$ the restriction of $\Phi(A)$ to the set of formulas in the language $\Sigma$.

Definition [1-6]. We denote by $[\Phi(A)]_{B}^{A}$ the diagram $\Phi(B)$ obtained by replacing a subset $A^{\prime} \subseteq A$ by a set $B^{\prime} \subseteq B$ of constants disjoint from $\Sigma$ and with $\left|A^{\prime}\right|=\left|B^{\prime}\right|$, where $A \backslash A^{\prime}=B \backslash B^{\prime}$. Similarly we call the consistent set of formulas denoted by $[\Phi(A)]_{X}^{A}$ the type $\Phi(X)$ if it is the result of a bijective substitution into $\Phi(A)$ of variables of $X$ for the constants in $A$. In this case, we say that $\Phi(B)$ is a copy of $\Phi(A)$ and a representative of $\Phi(X)$. We also denote the diagram $\Phi(A)$ by $[\Phi(X)]_{A}^{X}$.

Remark. If the vocabulary contains functional symbols then diagrams $\Phi(A)$ containing equalities and inequalities of terms can generate both finite and infinite structures. The same effect is observed for purely predicate vocabularies if it is written in $\Phi(A)$ that the model for $\Phi(A)$ should be infinite. For instance, diagrams containing axioms for finitely axiomatizable theories have this property.

By the definition, for any diagram $\Phi(A)$, each constant symbol in $\Sigma$ appears in some formula of $\Phi(A)$. Thus, $\Phi(A)$ can be considered as $\Phi(A \cup K)$, where $K$ is the set of constant symbols in $\Sigma$.

We now give conditions on a partial ordering of a collection of diagrams which suffice for it to determine a structure. We modify some of the conditions for structures by $d$ to signify they are conditions on diagrams not structures. 
Definition [1-6]. Let $\Sigma$ be a vocabulary. We say that $\left(\mathbf{D}_{0} ; \leqslant\right)$ (or $\left.\mathbf{D}_{0}\right)$ is generic, or generative, if $\mathbf{D}_{0}$ is a class of $\Sigma$-diagrams of finite sets so that $\mathbf{D}_{0}$ is partially ordered by a binary relation $\leqslant$ such that $\leqslant$ is preserved by bijective substitutions, i. e., if $\Phi(A) \leqslant \Psi(B)$, and $A^{\prime} \subseteq B^{\prime}$ such that $[\Phi(A)]_{A^{\prime}}^{A}=\Phi\left(A^{\prime}\right)$ and $[\Psi(B)]_{B^{\prime}}^{B}=\Psi\left(B^{\prime}\right)$ are defined, then $[\Phi(A)]_{A^{\prime}}^{A},[\Psi(B)]_{B^{\prime}}^{B}$ are in $\mathbf{D}_{0}$ and $[\Phi(A)]_{A^{\prime}}^{A} \leqslant[\Psi(B)]_{B^{\prime}}^{B}{ }^{1}$ Furthermore:

(i) if $\Phi(A) \in \mathbf{D}_{0}$ then for any quantifier free formula $\varphi(\bar{x})$ and any tuple $\bar{a} \in A$ either $\varphi(\bar{a}) \in \Phi(A)$ or $\neg \varphi(\bar{a}) \in \Phi(A)$;

(ii) if $\Phi \leqslant \Psi$ then $\Phi \subseteq \Psi ;^{2}$

(iii) if $\Phi \leqslant \mathrm{X}, \Psi \in \mathbf{D}_{0}$, and $\Phi \subseteq \Psi \subseteq \mathrm{X}$, then $\Phi \leqslant \Psi$;

(iv) some diagram $\Phi_{0}(\emptyset)$ is the least element of the system $\left(\mathbf{D}_{0} ; \leqslant\right)$, and $\mathbf{D}_{0} \backslash\left\{\Phi_{0}(\emptyset)\right\}$ is nonempty;

(v) (the d-amalgamation property) for any diagrams $\Phi(A), \Psi(B), \mathrm{X}(C) \in \mathbf{D}_{0}$, if there exist injections $f_{0}: A \rightarrow B$ and $g_{0}: A \rightarrow C$ with $[\Phi(A)]_{f_{0}(A)}^{A} \leqslant \Psi(B)$ and $[\Phi(A)]_{g_{0}(A)}^{A} \leqslant \mathrm{X}(C)$, then there are a diagram $\Theta(D) \in \mathbf{D}_{0}$ and injections $f_{1}: B \rightarrow D$ and $g_{1}: C \rightarrow D$ for which $[\Psi(B)]_{f_{1}(B)}^{B} \leqslant \Theta(D),[\mathrm{X}(C)]_{g_{1}(C)}^{C} \leqslant \Theta(D)$ and $f_{0} \circ f_{1}=g_{0} \circ g_{1}$; the diagram $\Theta(D)$ is called the amalgam of $\Psi(B)$ and $\mathrm{X}(C)$ over the diagram $\Phi(A)$ and witnessed by the four maps $\left(f_{0}, g_{0}, f_{1}, g_{1}\right)$;

(vi) (the local realizability property) if $\Phi(A) \in \mathbf{D}_{0}$ and $\Phi(A) \vdash \exists x \varphi(x)$, then there are a diagram $\Psi(B) \in \mathbf{D}_{0}$, $\Phi(A) \leqslant \Psi(B)$, and an element $b \in B$ for which $\Psi(B) \vdash \varphi(b)$;

(vii) (the $d$-uniqueness property) for any diagrams $\Phi(A), \Psi(B) \in \mathbf{D}_{0}$ if $A \subseteq B$ and the set $\Phi(A) \cup \Psi(B)$ is consistent then $\Phi(A)=\{\varphi(\bar{b}) \in \Psi(B) \mid \bar{b} \in A\}$.

A diagram $\Phi$ is called a strong subdiagram of a diagram $\Psi$ if $\Phi \leqslant \Psi$.

A diagram $\Phi(A)$ is said to be (strongly) embeddable in a diagram $\Psi(B)$ if there is an injection $f: A \rightarrow B$ such that $[\Phi(A)]_{f(A)}^{A} \subseteq \Psi(B)\left([\Phi(A)]_{f(A)}^{A} \leqslant \Psi(B)\right)$. The injection $f$, in this instance, is called a (strong) embedding of diagram $\Phi(A)$ in diagram $\Psi(B)$ and is denoted by $f: \Phi(A) \rightarrow \Psi(B)$. A diagram $\Phi(A)$ is said to be (strongly) embeddable in a structure $\mathcal{M}$ if $\Phi(A)$ is (strongly) embeddable in some diagram $\Psi(B)$, where $\mathcal{M} \models \Psi(B)$. The corresponding embedding $f: \Phi(A) \rightarrow \Psi(B)$, in this case, is called a (strong) embedding of diagram $\Phi(A)$ in structure $\mathcal{M}$ and is denoted by $f: \Phi(A) \rightarrow \mathcal{M}$.

Let $\mathbf{D}_{0}$ be a class of diagrams, $\mathbf{P}_{0}$ be a class of structures of some language, and $\mathcal{M}$ be a structure in $\mathbf{P}_{0}$. The class $\mathbf{D}_{0}$ is cofinal in the structure $\mathcal{M}$ if for each finite set $A \subseteq M$, there are a finite set $B, A \subseteq B \subseteq M$, and a diagram $\Phi(B) \in \mathbf{D}_{0}$ such that $\mathcal{M}=\Phi(B)$. The class $\mathbf{D}_{0}$ is cofinal in $\mathbf{P}_{0}$ if $\mathbf{D}_{0}$ is cofinal in every structure of $\mathbf{P}_{0}$. We denote by $\mathbf{K}\left(\mathbf{D}_{0}\right)$ the class of all structures $\mathcal{M}$ with the condition that $\mathbf{D}_{0}$ is cofinal in $\mathcal{M}$, and by $\mathbf{P}$ a subclass of $\mathbf{K}\left(\mathbf{D}_{0}\right)$ such that each diagram $\Phi \in \mathbf{D}_{0}$ is true in some structure in $\mathbf{P}$.

Now we extend the relation $\leqslant$ from the generative class $\left(\mathbf{D}_{0} ; \leqslant\right)$ to a class of subsets of structures in the class $\mathbf{K}\left(\mathbf{D}_{0}\right)$.

Let $\mathcal{M}$ be a structure in $\mathbf{K}\left(\mathbf{D}_{0}\right), A$ and $B$ be finite sets in $\mathcal{M}$ with $A \subseteq B$. We call $A$ a strong subset of the set $B$ (in the structure $\mathcal{M}$ ), and write $A \leqslant B$, if there exist diagrams $\Phi(A), \Psi(B) \in \mathbf{D}_{0}$, for which $\Phi(A) \leqslant \Psi(B)$ and $\mathcal{M} \models \Psi(B)$.

A finite set $A$ is called a strong subset of a set $M_{0} \subseteq M$ (in the structure $\mathcal{M}$ ), where $A \subseteq M_{0}$, if $A \leqslant B$ for any finite set $B$ such that $A \subseteq B \subseteq M_{0}$ and $\Phi(A) \subseteq \Psi(B)$ for some diagrams $\Phi(A), \Psi(B) \in \mathbf{D}_{0}$ with $\mathcal{M} \models \Psi(B)$. If $A$ is a strong subset of $M_{0}$ then, as above, we write $A \leqslant M_{0}$. If $A \leqslant M$ in $\mathcal{M}$ then we refer to $A$ as a self-sufficient set (in $\mathcal{M}$ ).

Notice that, by the $d$-uniqueness property, the diagrams $\Phi(A)$ and $\Psi(B)$ specified in the definition of strong subsets are defined uniquely. A diagram $\Phi(A) \in \mathbf{D}_{0}$, corresponding to a self-sufficient set $A$ in $\mathcal{M}$, is said to be a self-sufficient diagram (in $\mathcal{M})$.

Definition [1-6]. class $\left(\mathbf{D}_{0} ; \leqslant\right)$ possesses the joint embedding property (JEP) if for any diagrams $\Phi(A)$, $\Psi(B) \in \mathbf{D}_{0}$, there is a diagram $\mathrm{X}(C) \in \mathbf{D}_{0}$ such that $\Phi(A)$ and $\Psi(B)$ are strongly embeddable in $\mathrm{X}(C)$.

Clearly, every generative class has JEP since JEP means the $d$-amalgamation property over the empty set.

Definition [1-6]. A structure $\mathcal{M} \in \mathbf{P}$ has finite closures with respect to the class $\left(\mathbf{D}_{0} ; \leqslant\right)$, or is finitely generated over $\Sigma$, if any finite set $A \subseteq M$ is contained in some finite self-sufficient set in $\mathcal{M}$, i. e., there is a finite set $B$ with $A \subseteq B \subseteq M$ and $\Psi(B) \in \mathbf{D}_{0}$ such that $\mathcal{M} \models \Psi(B)$ and $\Psi(B) \leqslant \mathrm{X}(C)$ for any $\mathrm{X}(C) \in \mathbf{D}_{0}$ with $\mathcal{M}=\mathrm{X}(C)$ and $\Psi(B) \subseteq \mathrm{X}(C)$. A class $\mathbf{P}$ has finite closures with respect to the class $\left(\mathbf{D}_{0} ; \leqslant\right)$, or is finitely generated over $\Sigma$, if each structure in $\mathbf{P}$ has finite closures (with respect to $\left(\mathbf{D}_{0} ; \leqslant\right)$ ).

\footnotetext{
${ }^{1}$ Note that $\mathbf{D}_{0}$ is closed under bijective substitutions since $\leqslant$ is preserved by bijective substitutions and $\leqslant$ is reflexive.

${ }^{2}$ Note that $\Phi(A) \leqslant \Psi(B)$ implies $A \subseteq B$, since if $a \in A$ then $(a \approx a) \in \Phi(A)$, so $\Phi(A) \leqslant \Psi(B)$ implies $\Phi(A) \subseteq \Psi(B)$ and we have $(a \approx a) \in \Psi(B)$, whence $a \in B$.
} 
Clearly, an at most countable structure $\mathcal{M}$ has finite closures with respect to $\left(\mathbf{D}_{0} ; \leqslant\right)$ if and only if $M=\bigcup_{i \in \omega} A_{i}$ for some self-sufficient sets $A_{i}$ with $A_{i} \leqslant A_{i+1}, i \in \omega$.

Note that the finite closure property is defined modulo $\Sigma$ and does not correlate with the cardinalities of algebraic closures. For instance, if $\Sigma$ contains infinitely many constant symbols then $\operatorname{acl}(A)$ is always infinite whereas a finite set $A$ can or can not be extended to a self-sufficient set.

Besides, for the finite closures of sets $A$ we consider finite self-sufficient extensions $B$ in a given structure $\mathcal{M}$ with respect to $\left(\mathbf{D}_{0} ; \leqslant\right)$ only and $B$ can be both a universe of a substructure of $\mathcal{M}$ or not. Moreover, it is permitted that corresponding diagrams $\Psi(B)$ can have only finite, finite and infinite, or only infinite models.

Thus, for instance, a finitely axiomatizable theory without finite models and with a generative class $\left(\mathbf{D}_{0} ; \subseteq\right)$, containing diagrams for all finite sets and with axioms in diagrams, has identical finite closures whereas each diagram in $\mathbf{D}_{0}$ has only infinite models.

Definition [1-6]. A structure $\mathcal{M} \in \mathbf{K}\left(\mathbf{D}_{0}\right)$ is $\left(\mathbf{D}_{0} ; \leqslant\right)$-generic, or a generic limit for the class $\left(\mathbf{D}_{0} ; \leqslant\right)$ and denoted by $\operatorname{glim}\left(\mathbf{D}_{0} ; \leqslant\right)$, if it satisfies the following conditions:

(a) $\mathcal{M}$ has finite closures with respect to $\mathbf{D}_{0}$;

(b) if $A \subseteq M$ is a finite set, $\Phi(A), \Psi(B) \in \mathbf{D}_{0}, \mathcal{M} \models \Phi(A)$ and $\Phi(A) \leqslant \Psi(B)$, then there exists a set $B^{\prime} \leqslant M$ such that $A \subseteq B^{\prime}$ and $\mathcal{M} \models \Psi\left(B^{\prime}\right)$.

Clearly, uncountable $\left(\mathbf{D}_{0} ; \leqslant\right)$-generic structures can be non-isomorphic. Indeed, for instance, all infinite structures in the empty language are generic for a given generative class although these structures are nonisomorphic for distinct cardinalities. But, as the following theorem shows, they are isomorphic for at most countable cases.

Theorem 1.1 [1-6]. For any generative class $\left(\mathbf{D}_{0} ; \leqslant\right)$ with at most countably many diagrams whose copies form $\mathbf{D}_{0}$, there exists at most countable $\left(\mathbf{D}_{0} ; \leqslant\right)$-generic structure, unique up to isomorphism.

Theorem 1.2 [1-6]. Every $\omega$-homogeneous structure $\mathcal{M}$ is $\left(\mathbf{D}_{0} ; \leqslant\right)$-generic for some generative class $\left(\mathbf{D}_{0} ; \leqslant\right)$.

Thus any first-order theory has a generic model and therefore can be represented by it.

\section{Elementary equivalence and elementary embeddability}

Recall that structures $\mathcal{M}_{1}$ and $\mathcal{M}_{2}$ in a language $\Sigma$ are elementarily equivalent (denoted by $\mathcal{M}_{1} \equiv \mathcal{M}_{2}$ ) if for any sentence $\varphi$ in the language $\Sigma, \mathcal{M}_{1} \models \varphi$ if and only if $\mathcal{M}_{2} \models \varphi$.

Definition [11]. Let $\mathcal{M}_{1}$ and $\mathcal{M}_{2}$ be structures in a language $\Sigma$. An injective map $f: X \rightarrow M_{2}$, where $X \subseteq M_{1}$, is a partial isomorphism of $\mathcal{M}_{1}$ into $\mathcal{M}_{2}$ if for every elements $a_{1}, \ldots, a_{n} \in X$ the following conditions hold:

1) for any functional symbol $F^{(n)} \in \Sigma$ and correspondent operations $F_{\mathcal{M}_{1}}$ and $F_{\mathcal{M}_{2}}$ in $\mathcal{M}_{1}$ and $\mathcal{M}_{2}$, respectively,

$$
f\left(F_{\mathcal{M}_{1}}\left(a_{1}, \ldots, a_{n}\right)\right)=F_{\mathcal{M}_{2}}\left(f\left(a_{1}\right), \ldots, f\left(a_{n}\right)\right) ;
$$

2) for any predicate symbol $P^{(n)} \in \Sigma$ and correspondent predicates $P_{\mathcal{M}_{1}}$ and $P_{\mathcal{M}_{2}}$ in $\mathcal{M}_{1}$ and $\mathcal{M}_{2}$, respectively,

$$
\left(a_{1}, \ldots, a_{n}\right) \in P_{\mathcal{M}_{1}} \Leftrightarrow\left(f\left(a_{1}\right), \ldots, f\left(a_{n}\right)\right) \in P_{\mathcal{M}_{2}} .
$$

A partial isomorphism $f: X \rightarrow M_{2}$ is called finite if the set $X$ is finite.

The set of finite partial isomorphisms of $\mathcal{M}_{1}$ into $\mathcal{M}_{2}$ is denoted by $P\left(\mathcal{M}_{1}, \mathcal{M}_{2}\right)$.

The following well-known theorem uses the Fraïssé-Taimanov-Ehrenfeucht overturning method [7-10]. It is broadly used, in particular, in [12].

Theorem 2.1 [11]. Let $\mathcal{M}_{1}$ and $\mathcal{M}_{2}$ be structures in a language $\Sigma$. The following conditions are equivalent:

(1) the structures $\mathcal{M}_{1}$ and $\mathcal{M}_{2}$ are elementarily equivalent;

(2) for any $n \in \omega$ and any finite language $\Sigma_{0} \subseteq \Sigma$ there are nonempty sets $Z_{1}\left(\Sigma_{0}, n\right), \ldots, Z_{n}\left(\Sigma_{0}, n\right)$ of finite partial isomorphisms of $\left.\mathcal{M}_{1}\right|_{\Sigma_{0}}$ into $\left.\mathcal{M}_{2}\right|_{\Sigma_{0}}$ such that for any $f \in Z_{i}\left(\Sigma_{0}, n\right), 1 \leq i<n$, and for any a $\in M_{1}$, $b \in M_{2}$ there are $g_{1}, g_{2} \in Z_{i+1}\left(\Sigma_{0}, n\right)$, for which $a \in \delta_{g_{1}}, b \in \rho_{g_{2}}$ and $f \subseteq g_{1} \cap g_{2}$.

Notice that considering $\left(\mathbf{D}_{i} ; \leqslant_{i}\right)$-generic structures $\mathcal{M}_{i}$ in a language $\Sigma, i=1$, we take elements for extensions $g_{1}, g_{2} \in Z_{i+1}\left(\Sigma_{0}, n\right)$ in diagrams $\Phi(A)$ and $\Psi(B)$ in generative classes satisfying $\mathcal{M}_{1} \models \Phi(A)$ and $\mathcal{M}_{2}=\Psi(B)$. Moreover, since the sets $A$ and $B$ are finite, we can replace addition of elements $a$ and $b$ by addition of self-sufficient sets $A$ and $B$. Finite partial isomorphisms $f: X \rightarrow M_{2}$ with $X=A$ or $\rho_{f}=B$ are called coordinated with given generative classes, coordinated generic, or simply generic.

The set of generic finite partial isomorphisms of $\mathcal{M}_{1}$ into $\mathcal{M}_{2}$ is denoted by $\operatorname{PG}\left(\mathcal{M}_{1}, \mathcal{M}_{2}\right)$. 
We have $\mathrm{PG}\left(\mathcal{M}_{1}, \mathcal{M}_{2}\right) \subseteq P\left(\mathcal{M}_{1}, \mathcal{M}_{2}\right)$ and each partial isomorphism in $P\left(\mathcal{M}_{1}, \mathcal{M}_{2}\right)$ is extensible till a partial isomorphism in $\mathrm{PG}\left(\mathcal{M}_{1}, \mathcal{M}_{2}\right)$. Thus, for generic structures in Theorem 2.1 it suffices to consider generic finite partial isomorphisms in $\operatorname{PG}\left(\mathcal{M}_{1}, \mathcal{M}_{2}\right)$, with their restrictions, and a modification of that theorem holds allowing syntactically, in terms of generative classes, characterize the elementary equivalence for generic structures. Below we consider that generic modification, whose proof can be easily obtained from the proof of [11, Theorem 5.1.1].

Theorem 2.2 Let $\mathcal{M}_{i}$ be $\left(\mathbf{D}_{i} ; \leqslant_{i}\right)$-generic structures in a language $\Sigma, i=1,2$. The following conditions are equivalent:

(1) the structures $\mathcal{M}_{1}$ and $\mathcal{M}_{2}$ are elementarily equivalent;

(2) for any $n \in \omega$ and any finite language $\Sigma_{0} \subseteq \Sigma$ there are nonempty sets $Z_{1}\left(\Sigma_{0}, n\right), \ldots, Z_{n}\left(\Sigma_{0}, n\right)$ of restrictions of generic finite partial isomorphisms of $\mathcal{M}_{1} \mid \Sigma_{0}$ into $\left.\mathcal{M}_{2}\right|_{\Sigma_{0}}$ such that the following condition holds:

(*) for any $f \in Z_{i}\left(\Sigma_{0}, n\right), 1 \leq i<n$, and for any $a \in M_{1}, b \in M_{2}$ there are $g_{1}, g_{2} \in Z_{i+1}\left(\Sigma_{0}, n\right)$, for which $a \in \delta_{g_{1}}, b \in \rho_{g_{2}}$ and $f \subseteq g_{1} \cap g_{2}$.

Remark 2.3. Following Theorem 2.2 and adding for any $f \in Z_{i}\left(\Sigma_{0}, n\right)$ and for any $a \in M_{1}, b \in M_{2}$ all elements in some self-sufficient sets $A \supset \delta_{f} \cup\{a\}$ and $B \supset \rho_{f} \cup\{b\}$ we can consider sequences $Z_{1}\left(\Sigma_{0}, n\right), \ldots$, $Z_{n}\left(\Sigma_{0}, n\right)$ of nonempty families of generic finite partial isomorphisms with the property of sequential extensions by $g_{1}, g_{2} \in Z_{i+1}\left(\Sigma_{0}, n\right)$ with $a \in \delta_{g_{1}}, b \in \rho_{g_{2}}$ and $f \subseteq g_{1} \cap g_{2}$.

Proposition 2.4. If $\mathcal{M}_{i}$ are elementarily equivalent $\left(\mathbf{D}_{i} ; \leqslant_{i}\right)$-generic structures, $i=1,2$, then the classes $\left(\mathbf{D}_{i} ; \leqslant_{i}\right)$ can be extended, with some extensions of their diagrams, till a common generative class $\left(\mathbf{D}_{0} ; \leqslant\right)$.

Proof. Since $\mathcal{M}_{1} \equiv \mathcal{M}_{2}$, complete diagrams $\Phi^{*}(A)$ for finite sets in $\mathcal{M}_{1}$ and in $\mathcal{M}_{2}$ can be collected for a homogeneous model $\mathcal{M}$ of the theory $\operatorname{Th}\left(\mathcal{M}_{1}\right)=\operatorname{Th}\left(\mathcal{M}_{2}\right)$ realizing the complete types $\Phi^{*}(X)$. The complete diagrams for $\mathcal{M}$ form the required generative class $\left(\mathbf{D}_{0} ; \subseteq\right)$.

Proposition 2.4 immediately implies

Corollary 2.5. Any elementarily equivalent generic structures are isomorphic to some restrictions of a common generic structure.

Since any countable structure has a countable homogeneous elementary extension and homogeneous structures are generic, Corollary 2.5 has the following modification:

Corollary 2.6. Any elementarily equivalent countable structures are isomorphic to some restrictions of a common (countable) generic structure.

Recall that a substructure $\mathcal{M}_{1}=\left\langle M_{1} ; \Sigma\right\rangle$ of $\mathcal{M}_{2}=\left\langle M_{2} ; \Sigma\right\rangle$ is called an elementary substructure (denoted by $\left.\mathcal{M}_{1} \preccurlyeq \mathcal{M}_{2}\right)$, if for any formula $\varphi\left(x_{1}, \ldots, x_{n}\right)$ in the language $\Sigma$ and for any elements $a_{1}, \ldots, a_{n} \in M_{1}$ the condition $\mathcal{M}_{1} \models \varphi\left(a_{1}, \ldots, a_{n}\right)$ is equivalent to $\mathcal{M}_{2} \models \varphi\left(a_{1}, \ldots, a_{n}\right)$. Here the structure $\mathcal{M}_{2}$ is an elementary extension of $\mathcal{M}_{1}$. If $M_{1} \neq M_{2}$, we write $\mathcal{M}_{1} \prec \mathcal{M}_{2}$ instead of $\mathcal{M}_{1} \preccurlyeq \mathcal{M}_{2}$. If $\mathcal{M}_{1} \subseteq \mathcal{M}_{2}$ and the condition $\mathcal{M}_{1} \preccurlyeq \mathcal{M}_{2}\left(\mathcal{M}_{1} \prec \mathcal{M}_{2}\right)$ does not hold, we write $\mathcal{M}_{1} \npreceq \mathcal{M}_{2}$ (respectively $\left.\mathcal{M}_{1} \nprec \mathcal{M}_{2}\right)$.

The following well-known Tarski-Vaught test $[11,13]$ is used for the checking that a substructure is an elementary one.

Theorem 2.7. Let $\mathcal{M}_{1}$ and $\mathcal{M}_{2}$ be structures in a language $\Sigma, \mathcal{M}_{1} \subseteq \mathcal{M}_{2}$. The following conditions are equivalent:

(1) $\mathcal{M}_{1} \preccurlyeq \mathcal{M}_{2}$;

(2) for any formula $\varphi\left(x_{0}, x_{1}, \ldots, x_{n}\right)$ in the language $\Sigma$ and for any elements $a_{1}, \ldots, a_{n} \in M_{1}$, if $\mathcal{M}_{2} \models \exists x_{0} \varphi\left(x_{0}, a_{1}, \ldots, a_{n}\right)$ then there is an element $a_{0} \in M_{1}$ such that $\mathcal{M}_{2}=\varphi\left(a_{0}, a_{1}, \ldots, a_{n}\right)$.

In the following theorem, we obviously modify Theorem 2.7 for generic cases.

Theorem 2.8. Let $\mathcal{M}_{1}$ be a $\left(\mathbf{D}_{1} ; \leqslant_{1}\right)$-generic structures in a language $\Sigma, \mathcal{M}_{1} \subseteq \mathcal{M}_{2}$. The following conditions are equivalent:

(1) $\mathcal{M}_{1} \preccurlyeq \mathcal{M}_{2}$;

(2) for any formula $\varphi\left(x_{0}, x_{1}, \ldots, x_{n}\right)$ in the language $\Sigma$ and for any elements $a_{1}, \ldots, a_{n}$ forming a selfsufficient set $A \leqslant_{1} M_{1}$, if $\mathcal{M}_{2} \models \exists x_{0} \varphi\left(x_{0}, a_{1}, \ldots, a_{n}\right)$ then there is an element $a_{0} \in M_{1}$ in a self-sufficient set $B \leqslant_{1} M_{1}$ such that $A \leqslant_{1} B$ and $\mathcal{M}_{2} \models \varphi\left(a_{0}, a_{1}, \ldots, a_{n}\right)$.

Remark 2.9. If in Theorem 2.8 the diagrams $\Phi(A), \Psi(B) \in \mathbf{D}_{1}$, for the sets $A$ and $B$, force the complete types $\operatorname{tp}(A), \operatorname{tp}(B)$, respectively, we take formulas $\exists x_{0} \varphi\left(x_{0}, a_{1}, \ldots, a_{n}\right)$ and $\varphi\left(a_{0}, a_{1}, \ldots, a_{n}\right)$ which are forced by $\Phi(A)$ and $\Psi(B)$, respectively.

Recall that an elementary embedding of a structure $\mathcal{M}_{1}$ into a structure $\mathcal{M}_{2}$ of the same language $\Sigma$ is a map $f: M_{1} \rightarrow M_{2}$ such that for every $\Sigma$-formula $\varphi\left(x_{1}, \ldots, x_{n}\right)$ and all elements $a_{1}, \ldots, a_{n}$ of $M_{1}, \mathcal{M}_{1} \models \varphi\left(a_{1}, \ldots, a_{n}\right)$ if and only if $\mathcal{M}_{2} \models \varphi\left(f\left(a_{1}\right), \ldots, f\left(a_{n}\right)\right)$. In such a case, $f$ is really an embedding denoted by $f: \mathcal{M}_{1} \rightarrow \mathcal{M}_{2}$ and for $\mathcal{M}_{1}$ and $\mathcal{M}_{2}$ we say that $\mathcal{M}_{1}$ is elementarily embeddable into $\mathcal{M}_{2}$. 
Similarly to Theorems 2.7 and 2.8, the following theorems characterize the elementary embeddability in general case and for generic structures, respectively.

Theorem 2.10. Let $\mathcal{M}_{1}$ and $\mathcal{M}_{2}$ be structures in a language $\Sigma, f: \mathcal{M}_{1} \rightarrow \mathcal{M}_{2}$ be an embedding. The following conditions are equivalent:

(1) the embedding $f$ is elementary;

(2) for any formula $\varphi\left(x_{0}, x_{1}, \ldots, x_{n}\right)$ in the language $\Sigma$ and for any elements $a_{1}, \ldots, a_{n} \in M_{1}$, if $\mathcal{M}_{2} \models \exists x_{0} \varphi\left(x_{0}, f\left(a_{1}\right), \ldots, f\left(a_{n}\right)\right)$ then there is an element $a_{0} \in M_{1}$ such that $\mathcal{M}_{2} \models \varphi\left(f\left(a_{0}\right), f\left(a_{1}\right), \ldots, f\left(a_{n}\right)\right)$.

Theorem 2.11. Let $\mathcal{M}_{1}$ be a $\left(\mathbf{D}_{1} ; \leqslant_{1}\right)$-generic structure in a language $\Sigma$, and $f: \mathcal{M}_{1} \rightarrow \mathcal{M}_{2}$ be an embedding. The following conditions are equivalent:

(1) the embedding $f$ is elementary;

(2) for any formula $\varphi\left(x_{0}, x_{1}, \ldots, x_{n}\right)$ in the language $\Sigma$ and for any elements $a_{1}, \ldots, a_{n}$ forming a selfsufficient set $A \leqslant_{1} M_{1}$, if $\mathcal{M}_{2}=\exists x_{0} \varphi\left(x_{0}, f\left(a_{1}\right), \ldots, f\left(a_{n}\right)\right)$ then there is an element $a_{0} \in M_{1}$ in a self-sufficient set $B \leqslant 1 M_{1}$ such that $A \leqslant_{1} B$ and $\mathcal{M}_{2}=\varphi\left(f\left(a_{0}\right), f\left(a_{1}\right), \ldots, f\left(a_{n}\right)\right)$.

\section{Acknowledgements}

The research was partially supported by Committee of Science in Education and Science Ministry of the Republic of Kazakhstan (Grant No. AP05132546) and by Russian Foundation for Basic Researches (Grant No. 17-01-00531).

\section{References}

1 Судоплатов С.В. Классификация счетных моделей полных теорий / С.В. Судоплатов. - Новосибирск: Изд-во НГТУ, 2014.

2 Судоплатов С.В. Синтаксический подход к построению генерических моделей / С.В. Судоплатов // Алгебра и логика. - 2007. - Т. 46. - № 2. - С. 244-268.

3 Sudoplatov S.V. Generative and pre-generative classes. Proceedings of the 10th Panhellenic Logic Symposium, June 11-15, 2015, Samos, Greece, University of Aegean, University of Crete, and University of Athens, 2015. - P. 30-34.

4 Sudoplatov S.V. Generative classes generated by sets of diagrams. Algebra and Model Theory 10. Collection of papers. Edited by A.G. Pinus, K.N. Ponomaryov, S.V. Sudoplatov, E.I. Timoshenko. - Novosibirsk: NSTU, 2015. - P. 163-174.

5 Sudoplatov, S.V., Kiouvrekis, Y. \& Stefaneas, P. (2017). Generic constructions and generic limits. Algebraic Modeling of Topological and Computational Structures and Applications / Springer Proceedings in Mathematics \& Statistics, 219. S. Lambropoulou (Ed.) et al. Berlin: Springer Int. Publ. - P. 375-398.

6 Kiouvrekis Y. Definable sets in generic structures and their cardinalities / Y. Kiouvrekis, P. Stefaneas, S.V. Sudoplatov // Siberian Advances in Math. - 2018. - Vol. 28. - 1. - P. 39-52.

7 Fraïssé R. Sur les rapports entre la théorie des relations et la sémantique au sens de A. Tarski / R.Fraïssé // Collogue de Logique mathématique. - Paris, 1952.

8 Fraïssé R. Sur les classifications des systems de relations / R.Fraïssé. Publications Sc. de l'Université D'Alger I, 1954. - No. 1.

9 Тайманов А.Д. Характеристики аксиоматизируемых классов моделей / А.Д. Тайманов // Алгебра и логика. - 1962. - Т. 1. - № 4. - С. 5-31.

10 Ehrenfeucht A. Applications of games to the completeness problem / A.Ehrenfeucht // Fundamenta Mathematicae. - 1961. - Vol. XLIX. - No. 2. - P. 129-141.

11 Ершов Ю.Л. Математическая логика / Ю.Л. Ершов, Е.А. Палютин. - М.: Физматлит, 2011. - 356 с.

12 Корольков Ю.Д. Представление моделей конечными деревьями / Ю.Д. Корольков // Известия Иркутского государственного университета. Сер. Математика. - 2012. - Т. 5. — № 1. - С. 48-56.

13 Tarski A. Arithmetical extensions of relational systems / A.Tarski, R.L.Vaught // Comp. Math. - 1957. - Vol. 13. - P. 81-102. 


\title{
Элементарлық енгізілуді және элементарлық эквиваленттілікті сақтайтын генерикалық құрылымдар туралы
}

\begin{abstract}
Мақалада генерикалық құрылымдар үшін элементарлық эквиваленттілік және элементарлық енгізілу критерийлері қарастырылды. Олар үшін жалпы жағдайдағы классикалық сипаттама қолданылды. Элементарлы эквивалентті критерийі Фраиссе-Тайманов-Эренфойхтың жақсы танымал «ауыстыру» әдісінде негізделген. Элементарлық енгізілу критерийінде Тарский-Вооттың танымал тесті пайдаланылды.
\end{abstract}

Kiлm сөздер: генерикалық құрылымдар, элементарлық эквиваленттілік, Фраиссе-Тайманов-Эренфойхтың әдісі, элементарлық енгізілу, Тарский-Воот тесті.

\section{С.В. Судоплатов}

\section{О генерических структурах, сохраняющих элементарную эквивалентность и элементарную вложимость}

В статье рассмотрены критерии элементарной эквивалентности и элементарной вложимости для генерических структур, которые используют классические характеризации для общего случая. Критерий элементарной эквивалентности базирован на хорошо известном методе «перекидывания» ФраиссеТайманова-Эренфойхта, а критерий элементарной вложимости - на известном тесте Тарского-Воота.

Ключевые слова: генерические структуры, элементарная вложимость, метод Фраиссе-ТаймановаЭренфойхта, тест Тарского-Воота.

\section{References}

1 Sudoplatov, S.V. (2014). Klassifikatsiia schetnykh modelei polnykh teorii /Classification of Countable Models of Complete Theories]. Novosibirsk: Izdatelstvo NHTU [in Russian].

2 Sudoplatov, S.V. (2007). Sintaksicheskii podkhod k postroeniiu henericheskikh modelei [Syntactic approach to constructions of generic models]. Alhebra $i$ lohika - Algebra and Logic, Vol. 46, 2, 134-146 [in Russian].

3 Sudoplatov, S.V. (2015). Generative and pre-generative classes, Proceedings of the 10th Panhellenic Logic Symposium, June 11-15, 2015, Samos, Greece, University of Aegean, University of Crete, and University of Athens, p. 30-34.

4 Sudoplatov, S.V., Pinus, A.G., Ponomaryov, K.N., Sudoplatov, S.V., \& Timoshenko, E.I. (Eds.). (2015). Generative classes generated by sets of diagrams. Algebra and Model Theory 10. Novosibirsk: Izdatelstvo NHTU [in Russian].

5 Sudoplatov, S.V., Kiouvrekis, Y. \& Stefaneas, P. (2017). Generic constructions and generic limits. Algebraic Modeling of Topological and Computational Structures and Applications / Springer Proceedings in Mathematics \& Statistics, 219. S. Lambropoulou (Ed.) et al. Berlin: Springer Int. Publ.

6 Kiouvrekis, Y., Stefaneas, P., \& Sudoplatov, S.V. (2018). Definable sets in generic structures and their cardinalities. Siberian Advances in Math., Vol. 28, 1, 39-52.

7 Fraïssé, R. (1952). Sur les rapports entre la théorie des relations et la sémantique au sens de A.Tarski. Collogue de Logique mathématique. Paris.

8 Fraïssé, R. (1954). Sur les classifications des systems de relations. Publ. Sc. de l'Université D'Alger I, No. 1.

9 Taimanov, A.D. (1962). Kharakteristiki aksiomatiziruemykh klassov modelei [Characteristics of axiomatizable classes of models]. Alhbra i lohika - Algebra and Logic, Vol. 1, 4, 5-31 [in Russian]. 
10 Ehrenfeucht, A. (1961). Applications of games to the completeness problem. Fundamenta Mathematicae, Vol. XLIX, 2, 129-141.

11 Ershov, Yu.L., \& Palyutin, E.A. (2011). Matematicheskaia lohika [Mathematical logic]. Moscow: Fizmatlit [in Russian].

12 Korol'kov, Yu.D. (2012). Predstavlenie modelei konechnymi dereviami [Representation of models by finite trees]. Izvestiia Irkutskoho hosudarstvennoho universiteta. Seriia Matematika - Reports of Irkutsk State University. Series Mathematics, Vol. 5, 1, 48-56 [in Russian].

13 Tarski, A., \& Vaught, R.L. (1957). Arithmetical extensions of relational systems, Comp. Math., Vol. 13, 81-102. 